\title{
IMPACT OF ATHEROSCLEROTIC RISK FACTORS ON HISTOPATHOLOGICAL FEATURES OF ASPIRATED CORONARY THROMBI IN ST ELEVATION MYOCARDIAL INFARCTION PATIENTS UNDERGOING PRIMARY PERCUTANEOUS CORONARY INTERVENTION
}

\author{
Louie Fischer1, Elizabeth Joseph², Anoop Mathew³, Eapen Punnose ${ }^{4}$
}

${ }^{1}$ Associate Professor, Department of Cardiology, MOSC Medical College Hospital, Kolenchery, Kochi, Kerala. ${ }^{2}$ Associate Professor, Department of Pathology, MOSC Medical College Hospital, Kolenchery, Kochi, Kerala. ${ }_{3}^{3}$ Associate Professor, Department of Cardiology, MOSC Medical College Hospital, Kolenchery, Kochi, Kerala. 4 Professor, Department of Cardiology, MOSC Medical College Hospital, Kolenchery, Kochi, Kerala.

\section{ABSTRACT}

\section{BACKGROUND}

The disruption of the atherosclerotic plaque causes acute coronary thrombosis. Several modes of plaque disruption provoke this, foremost being fracture of the fibrous cap and superficial erosion of the intima, especially in those with hypertriglyceridaemia and diabetes. The present study was undertaken to determine the prevalence of various risk factors in a group of patients undergoing Primary Percutaneous Coronary Intervention (PPCI) and the impact of these risk factors on the histopathological composition of thrombus.

\section{MATERIALS AND METHODS}

107 consecutive patients with a diagnosis of ST elevation myocardial infarction (STEMI) presenting within 12 hours of index anginal symptoms undergoing primary percutaneous coronary intervention were included in the present study. Thrombus aspirated during PPCI was histopathologically analysed and classified as recent or lysed by well-accepted criteria and correlated with atherosclerotic risk factors.

\section{RESULTS}

Majority of the thrombus were lysed or organised. There was statistically significant association between hypertension and lysed or organised thrombus and there was a trend towards increased occurrence of recent thrombus in smokers.

\section{CONCLUSION}

Thrombus aspirated during PPCI in patients of STEMI were more often lysed or organised than recent. Among the various risk factors, systemic hypertension was associated with higher number of lysed or organised thrombus whereas smoking status was associated with a trend towards more number of recent thrombus.

\section{KEYWORDS}

Thrombus, STEMI, Risk Factors, PPCI.

HOW TO CITE THIS ARTICLE: Fischer L, Joseph E, Mathew A, et al. Impact of atherosclerotic risk factors on histopathological features of aspirated coronary thrombi in ST elevation myocardial infarction patients undergoing primary percutaneous coronary intervention. J. Evolution Med. Dent. Sci. 2016;5(77):5762-5765, DOI: 10.14260/jemds/2016/1299

\section{INTRODUCTION}

There has been considerable advances in the understanding of mechanisms underlying coronary thrombosis. The disruption of the atherosclerotic plaque causes acute coronary thrombosis. Several modes of plaque disruption provoke this, foremost being fracture of the fibrous cap. Another mode is superficial erosion of the intima, especially in those with hypertriglyceridaemia and diabetes. ${ }^{1}$

A number of variables such as systolic BP, Heart Rate, hyperglycaemia and oxidised LDL cholesterol levels increase at times of stress which in turn can lead to plaque disruption and coronary thrombosis. ${ }^{2}$

Financial or Other, Competing Interest: None.

Submission 29-07-2016, Peer Review 22-08-2016,

Acceptance 30-08-2016, Published 26-09-2016.

Corresponding Author:

Dr. Louie Fischer,

Associate Professor

Department of Cardiology,

MOSC Medical College Hospital

Kolenchery, Kochi, Kerala.

E-mail:drlouiefischer@yahoo.com

DOI: $10.14260 /$ jemds/2016/1299
Many of these have been considered as classical atherosclerotic risk factors. Each of these risk factors might have a different role in the aetiopathogenesis of coronary thrombosis.

As an example, in hypertensive patients, hyperactivity of sympathetic tone may promote atherosclerosis by worsening insulin resistance, through sympathetic vasoconstriction on glucose extraction in skeletal muscle, beta adrenoreceptormediated insulin resistance, and vascular rarefaction because of the closure of the smaller vessels due to vascular hypertrophy. Sympathetic hyperactivity itself also contributes to a higher risk of coronary spasm, and coronary thrombosis. ${ }^{3}$ However, the association of atherosclerotic risk factors with the thrombus composition in treated patients of ST elevation myocardial infarction (STEMI) has not been previously analysed.

Aim of the present study is to determine the prevalence of various risk factors in a group of patients undergoing Primary Percutaneous Coronary Intervention (PPCI) and the impact of these risk factors on the histopathological composition of thrombus. 


\section{METHODS}

107 consecutive patients with a diagnosis of STEMI presenting within 12 hours of index anginal symptoms undergoing primary percutaneous coronary intervention were included in the present study.

All patients were treated with aspirin $300 \mathrm{mg}$ and either Clopidogrel or one among the newer antiplatelet agents (Ticagrelor or Prasugrel) on admission.

Heparin and Glycoprotein IIb/IIIa receptor inhibitors were also used according to the institutional protocol. Angiogram using a $6 \mathrm{~F}$ guiding catheter was performed to identify the culprit lesion, then a 0.014 inch coronary guidewire was passed across the lesion. Before any other intervention, thrombus was aspirated with a thrombus aspiration catheter. The types and the number of stents and pre and post-balloon dilatations during angioplasty were according to the discretion of the operator. In multivessel disease, the vessel occluded with thrombus was considered as the culprit vessel for STEMI.

The aspirated material was immediately fixed in $10 \%$ formalin and sent for histopathological analysis. After fixation for 24 hours, the material was embedded in paraffin and processed. Serial sections of 5 microns were cut and stained with haematoxylin and eosin. The examining pathologist was blinded to the angiographic finding, the result of PCI and the clinical followup. The sections were analysed for the presence of aspirated thrombus. The thrombi were then categorised as recent or old according to the previously published and histopathologically accepted definitions. ${ }^{4}$ Fresh thrombus $(<1$ day) is composed of layered patterns of fibrin and intact platelets, erythrocytes and granulocytes. Older thrombus $(>1$ day) show karyorrhexis, necrosis and proliferation of smooth muscle cells. Thrombus material with a heterogenous composition was graded according to the age of the oldest part. Insufficient material precluded the classification of thrombi in some of the cases. Baseline demographic characteristics and risk factors were obtained.

The study was reviewed and approved by the independent ethics committee at MOSC Medical College Hospital, Kolenchery.

The statistics for measurement data (age, time, etc.) was summarised as central tendency and spread, commonly as mean and standard deviation. The events and proportions were summarised as frequencies. Significance tests for independent parameters were performed with z-test for means and medians, direct probabilities were taken for frequencies. The data analysis was performed with Minitab software and MS - Excel.

\section{RESULTS}

A total of 107 consecutive patients of STEMI from MOSC Medical College Hospital Kolenchery, a tertiary teaching institute from South India, were included. Mean age of the patients in the study was $54.93 \pm 13.19$ years. There were 94 (87.9\%) males. In the cohort, 34 (31.9\%) subjects were diabetic, 23 (21.5\%) had hypertension and 17 (15.9\%) had dyslipidaemia. Family history of CAD was positive in 11 (10.3\%) patients and 49 (45.8\%) patients were currently smoking (Table 1). Demographic pattern of the cohort in the study was typically a "real world" population presenting in the hospital with STEMI.

\begin{tabular}{|c|c|}
\hline N & 107 \\
\hline Age -Mean (St.Dev) & $54.93(13.19)$ \\
\hline Males n (\%) & $94(87.85)$ \\
\hline Risk factors & $34(31.78)$ \\
\hline Diabetes Mellitus n (\%) & $23(21.50)$ \\
\hline Hypertension n (\%) & $49(45.80)$ \\
\hline Current smoking n (\%) & $17(15.90)$ \\
\hline DLP n (\%) & $11(10.28)$ \\
\hline Family History n (\%) & Table 1: Demographics
\end{tabular}

In 57 cases $(51.8 \%)$, the culprit vessel was right coronary artery (RCA). Left anterior descending (LAD) artery and circumflex were occluded in 36 (32.7\%) and 13 (11.8\%) cases respectively (Table 2). Most cases (60.8\%) presented with inferior wall myocardial infarction (MI). 37.4\% had anterior wall MI and very few had posterior wall infarction (3.7\%). One subject (0.9\%) presented with Complete Heart Block (Table 3).

\begin{tabular}{|c|c|}
\hline $\mathrm{N}$ & 107 \\
\hline Mean Age & $54.93 \pm 13.19$ \\
\hline Males & $94(87.85 \%)$ \\
\hline Risk factors & $34(31.78 \%)$ \\
\hline Diabetes Mellitus & $23(21.50 \%)$ \\
\hline Hypertension & $49(45.80 \%)$ \\
\hline Current smoking & $17(15.90 \%)$ \\
\hline Dyslipidaemia & $11(10.28 \%)$ \\
\hline Family History \\
\hline \multicolumn{2}{|c|}{ Table 2 } \\
\hline
\end{tabular}

\begin{tabular}{|c|c|}
\hline Right Coronary Artery & $57(51.82 \%)$ \\
\hline Left Main & $1(0.91 \%)$ \\
\hline Circumflex & $13(11.82 \%)$ \\
\hline Left Anterior Descending & $36(32.73 \%)$ \\
\hline Obtuse Marginal & $1(0.91 \%)$ \\
\hline First Diagonal & $1(0.91 \%)$ \\
\hline Second Diagonal & $0(0 \%)$ \\
\hline Other/Ramus & $1(0.91 \%)$ \\
\hline Table 3: Distribution of Lesions by Vessels
\end{tabular}

Among the 107 samples processed, 5 consisted of only plaque. Of the rest 102 thrombi evaluated, 34 (31.8\%) were recent and 68 (63.6\%) were old (Table 4, Figure 1).

\begin{tabular}{|c|c|}
\hline Thrombus Type & $5(4.67 \%)$ \\
\hline Non-evaluable & $34(32.08 \%)$ \\
\hline Recent thrombus & $68(64.15 \%)$ \\
\hline Organised or Lysed & Table 4: Histopathological Outcome of Thrombi \\
\hline \multicolumn{2}{|c|}{}
\end{tabular}

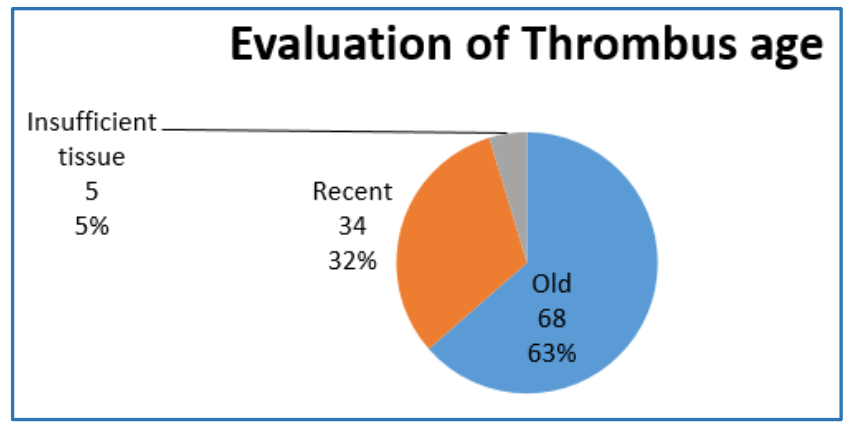

Fig. 1: Histopathological Classification of Thrombus 
Table 5 (Figure 3) shows the results of ODD's analysis for the effect of risk factors on thrombus ageing. Hypertension had an OR of 2.7 (95\% confidence interval, 0.56-5.89; p=0.009). The OR for smoking was 0.66 (95\% confidence interval 0.67 3.49; $\mathrm{p}=0.32$ ).

\begin{tabular}{|c|c|c|c|c|c|}
\hline & $\begin{array}{c}\text { Odds } \\
\text { Ratio }\end{array}$ & $\begin{array}{c}\mathbf{9 5 \%} \text { CI } \\
\text { Upper }\end{array}$ & $\begin{array}{c}\mathbf{9 5 \%} \text { CI } \\
\text { Lower }\end{array}$ & $\begin{array}{c}\text { Static } \\
\mathbf{Z}\end{array}$ & \\
\hline Diabetes & 1.42 & 3.53 & 0.57 & 0.75 & $\mathrm{p}=0.45$ \\
\hline $\begin{array}{c}\text { Hyperte } \\
\text { nsion }\end{array}$ & 2.70 & 5.89 & 0.56 & 1.66 & $\mathrm{p}=0.009$ \\
\hline Smoking & 0.66 & 3.49 & 0.67 & 0.98 & $\mathrm{p}=0.32$ \\
\hline $\begin{array}{c}\text { Dyslipid } \\
\text { aemia }\end{array}$ & 1.61 & 6.27 & 0.55 & 0.77 & $\mathrm{p}=0.44$ \\
\hline $\begin{array}{c}\text { Family } \\
\text { History }\end{array}$ & 1.38 & 8.23 & 0.50 & 0.45 & $\mathrm{p}=0.65$ \\
\hline \multicolumn{5}{|c|}{ Table 5: ODD's Analysis for effect of Risk } \\
\multicolumn{6}{|c|}{ Factors on Thrombus Ageing } \\
\hline
\end{tabular}

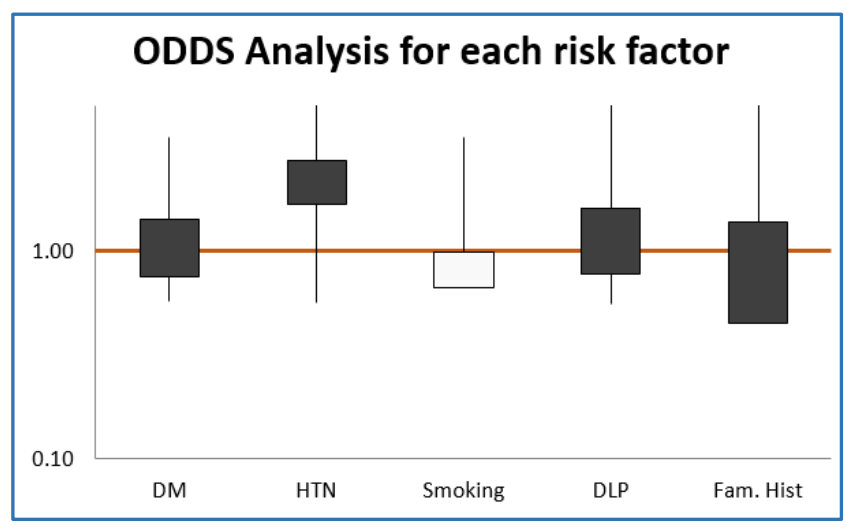

Fig. 3: ODD's Analysis of Risk Factors

\section{DISCUSSION}

In our study, majority of the patients (64\%) had old thrombus irrespective of the duration of the ischaemic symptoms. This is consistent with the findings from similar previous studies and confirms the concept that thrombus formation and its subsequent lysis or organisation may occur significantly before the onset of symptoms in acute coronary syndrome especially STEMI.5,6 The composition of most of the thrombi were heterogenous, showing in part features of fresh, lytic and organised thrombus, thus conceptually supporting the fact that coronary artery disease is a dynamic process.

Even though risk stratification in ACS is possible by angiographic grading of thrombus, the most powerful yet simplest method of stratification is based on clinical risk factors. In the present study since most of the patients are young adults and males, the comorbidity profile plays an important role. ODD's analysis is a comparison tool for stratified analysis of the effect of risk factors on the outcomes. In this case, we considered old thrombus as a positive event and recent thrombus as a negative event.

Our analysis revealed that hypertension leads to rapid lysis and organisation of the thrombus. Previously, Burke et al had reported a decreased frequency of acute thrombosis in hypertension-related sudden death due to coronary events whereas smoking was associated with increased frequency of acute thrombosis. ${ }^{7}$
In the present study, there was a trend towards higher percentage of fresh thrombus in smokers. Fusegawa et al had shown that platelets isolated from smokers exhibited an increased stimulated and spontaneous aggregation. ${ }^{8}$

Platelet $\alpha$-granule constituents, such as platelet factor- $4, \beta$ thromboglobulin, and platelet activating factor, are increased in the plasma of smokers, suggesting increased platelet activation.9,10,11 Barua et al using thromboelastography, demonstrated that acute cigarette smoking was associated with functional changes in platelets and these changes affected the dynamics of clot formation. ${ }^{12}$ These clots were more resistant to thrombolysis as compared with clots of nonsmokers. Smokers also have higher P2Y12 expression in platelet lysates than nonsmokers. ${ }^{13,14}$

All these point towards an aggressive platelet activation, adhesion and aggregation in smokers. The thrombus formed in such cigarette smoke exposed circulation will be resistant to the thrombolytic mechanism in the body. This might explain the higher percentage of fresh thrombus in smokers in our study.

Histopathological composition of thrombus behaves differently in the presence of individual risk factors in isolation than when the risk factors are present in combination (Table 6, Figure 6). This might be because of the complex interplay of the various aetiopathogenic mechanisms related to the risk factors.

\begin{tabular}{|c|c|c|c|c|c|}
\hline & $\begin{array}{c}\text { Odd's } \\
\text { Ratio }\end{array}$ & $\begin{array}{c}95 \% \text { CI } \\
\text { upper }\end{array}$ & $\begin{array}{c}95 \% \text { CI } \\
\text { lower }\end{array}$ & $\begin{array}{c}\text { Static } \\
\mathrm{Z}\end{array}$ & \\
\hline $\begin{array}{c}\text { DM } \\
\text { Exclusive }\end{array}$ & 0.43 & 1.49 & 0.12 & 1.34 & $\mathrm{P}=0.18$ \\
\hline $\begin{array}{c}\text { HTN } \\
\text { Exclusive }\end{array}$ & 0.11 & 1.55 & 0.01 & 1.64 & $\mathrm{P}=0.10$ \\
\hline $\begin{array}{c}\text { Smoking } \\
\text { Exclusive }\end{array}$ & 0.80 & 0.32 & 1.99 & 0.48 & $\mathrm{P}=0.63$ \\
\hline $\begin{array}{c}\text { DLP } \\
\text { Exclusive }\end{array}$ & 0.75 & 6.39 & 0.09 & 0.26 & $\mathrm{P}=0.79$ \\
\hline $\begin{array}{c}\text { Fam. Hist. } \\
\text { Exclusive }\end{array}$ & 0.19 & 2.91 & 0.01 & 1.20 & $\mathrm{P}=0.23$ \\
\hline $\begin{array}{c}\text { All } \\
\text { Positive }\end{array}$ & 1.42 & 78.13 & 0.03 & 0.17 & $\mathrm{P}=0.86$ \\
\hline \multicolumn{6}{|c|}{ Table 6: Analysis of Individual Risk Factors } \\
in Isolation (Exclusive)
\end{tabular}

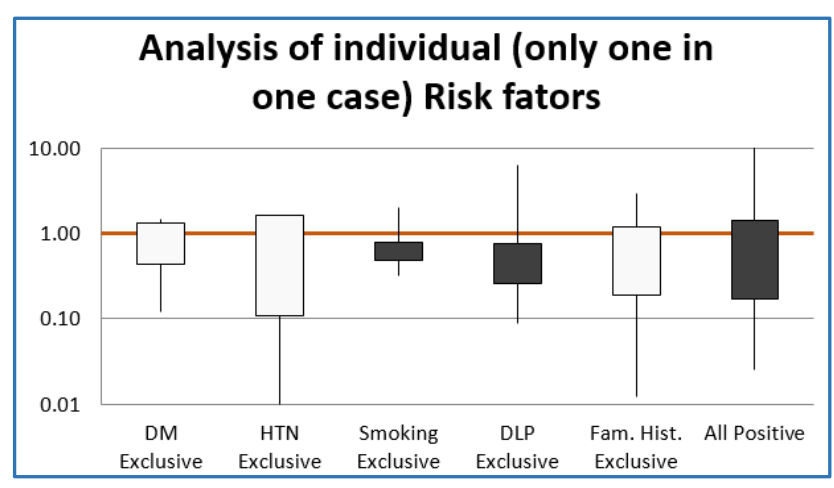

Fig. 6

To the best of our knowledge, this is the first study in Indian context to analyse the correlation between atherosclerotic risk factors and the histopathological composition of thrombus. 


\section{CONCLUSION}

Majority of the thrombi in STEMI patients undergoing PPCI were lysed/organised. Among the classical atherosclerotic risk factors, systemic hypertension leads to rapid lysis/organisation of the thrombus resulting in old thrombus whereas current smoking tends to delay thrombus lysis and organisation.

These findings require validation in a larger number of population with multiple risk factors.

\section{LIMITATIONS}

Novel and evolving risk factors that have been implicated in coronary atherosclerosis, including clotting factors such as plasminogen activator inhibitor, fibrinogen, von Willebrand factor antigen, platelet glycoprotein IIb/IIIa, gene polymorphism and lipid variants such as apolipoprotein $\mathrm{E}$ polymorphism and lipoprotein (a) might affect the coronary plaque morphology and have not been addressed in this study.

\section{REFERENCES}

1. Virmani R, Burke AP, Farb A, et al. Pathology of the vulnerable plaque. J Am Coll Cardiol 2006;47(8 Suppl):C13-8.

2. Manfredini R, Boari B, Salmi R, et al. Circadian rhythms and reperfusion in patients with acute ST-segment elevation myocardial infarction. JAMA 2005; 294(22): 2846-7.

3. Picariello C, Lazzeri C, Attana P, et al. The impact of hypertension on patients with acute coronary syndromes. Int J Hypertens, Article ID 563657 2011;2011:5636573.

4. Kramer MC, Rittersma SZ, de Winter RJ, et al. Relationship of thrombus healing to underlying plaque morphology in sudden coronary death. J Am Coll Cardiol 2010;55(2): 122-32.

5. Rittersma SZ, Van Der Wal AC, Koch KT, et al. Plaque instability frequently occurs days or weeks before occlusive coronary thrombosis: a pathological thrombectomy study in primary percutaneous coronary intervention. Circulation 2005;111(9):1160-5.
6. Kramer MC, van der Wal AC, Koch KT, et al. Histopathological features of aspirated thrombi after primary percutaneous coronary intervention in patients with ST-elevation myocardial infarction. PLOS ONE 2009;4(6):e5817.

7. Burke AP, Farb A, Malcom GT, et al. Coronary risk factors and plaque morphology in men with coronary disease who died suddenly. N Engl J Med 1997;336(18):1276-82.

8. Fusegawa Y, Goto S, Handa S, et al. Platelet spontaneous aggregation in platelet-rich plasma is increased in habitual smokers. Thromb Res 1999;93(6):271-8.

9. Blache D. Involvement of hydrogen and lipid peroxides in acute tobacco smoking-induced platelet hyperactivity. Am J Physiol 1995;268(2 Pt 2):H679-85.

10. Hung J, Lam JY, Lacoste L, et al. Cigarette smoking acutely increases platelet thrombus formation in patients with coronary artery disease taking aspirin. Circulation 1995;92(9):2432-6.

11. Benowitz NL, Fitzgerald GA, Wilson M, et al. Nicotine effects on eicosanoid formation and hemostatic function: comparison of transdermal nicotine and cigarette smoking. J Am Coll Cardiol 1993;22(4):1159-67.

12. Barua RS, Ambrose JA. Mechanisms of coronary thrombosis in cigarette smoke exposure. Arterioscler Thromb Vasc Biol 2013;33(7):1460-7.

13. Barua RS, Sy F, Srikanth S, et al. Effects of cigarette smoke exposure on clot dynamics and fibrin structure: an ex vivo investigation. Arterioscler Thromb Vasc Biol 2010; 30(1):75-9.

14. Barua RS, Sy F, Srikanth S, et al. Acute cigarette smoke exposure reduces clot lysis-association between altered fibrin architecture and the response to t-PA. Thromb Res 2010;126(5):426-30. 